\title{
9 \\ Cultural studies in the new South Africa
}

How we conceptualise future directions of cultural studies depends on how we have conceptualised the origins and genealogy of that discipline. In the UK, two stories of origins have emerged, the textual and the sociological. The future theorisation and analysis of South African cultural studies may follow either story. The textual version is probably dominant within British academia. It locates three texts, Richard Hoggart's The Uses of Literacy, E.P. Thompson's The Making of the English Working Class and Raymond Williams's Culture and Society, as the progenitors of cultural studies as an academic field. It is interesting that Raymond Williams has himself been one of the most energetic critics of this textualist version. In 'The Future of Cultural Studies', for instance, he argues forcefully that this textualist account is 'only the surface of the real development, and is moreover misleading.' Instead, Williams points to diverse adult education activities in the 1940s as the origins of cultural studies. His sociological account is illuminating even if one prefers to privilege the textual. Those texts were, as Linden Peach has observed,

written while their authors were working outside the mainstream in higher education: Hoggart was employed as a staff tutor in adult education at Hull University, E.P. Thompson was a staff tutor in the Yorkshire Workers Education Association and Raymond Williams was an Oxford staff tutor in the Sussex W.E.A. and an occasional summer school lecturer in Yorkshire. ${ }^{2}$

As Williams sees it, the core distinguishing characteristic of adult education projects of that period was that

Academics took out from their institutions university economics, or university English or university philosophy, and the people wanted 
to know what it was. This exchange didn't collapse into some simple populism: that these were all silly intellectual questions. Yet these new students insisted (1) that the relation of this to their own situation and experience had to be discussed, and (2) that there were areas in which the discipline itself might be unsatisfactory, and therefore they retained as a crucial principle the right to decide their own syllabus. (p. 156)

Recognising the intellectual significance of these non-university, nontextual contexts and origins for cultural studies is not very easy for contemporary professional academics in cultural studies. We often seem reluctant to address the complexities of the processes of institutionalisation, to perceive and theorise the extent to which our own intellectual formations are conditioned by our place within this institution. We may acknowledge that cultural studies historically derive from adult education institutions, and that these local institutions may have determined the forms of knowledge which once passed as cultural studies, but such institutional contingencies are rarely regarded as being of theoretical significance. What happens, though, if we follow Williams's suggestion and analyse how institutionalisation affects our practices?

I will return to issues of institutionalisation. I want now to ask what these non-textual, non-academic components of cultural studies might mean for a new South Africa. Among other things, they might send us to look for African cultural studies as it already exists outside the academy. It might mean that what South African academics 'appropriate' from the UK are not only aspects of its current theoretical capital but also insights inspired by the UK's social, educational and cultural history. ${ }^{3}$

I do not want to imply any direct parallel between the history of South Africa and that of the UK in the twentieth century: on the contrary. (Later I will address what I see as the dangers of applying theoretical paradigms developed in the UK, USA and Europe within a new South Africa.) But I do want to argue that the British historical experience of cultural studies - and the conflicting ways in which that experience can be interpreted are something from which South African academe can learn. Arriving in South Africa (in 1993), I was struck by the large size of South Africa's community-led adult education. The size, diversity and energy of community arts projects and civic organisations also impressed me. There is a lot of potential for developing an academic cultural studies that is symbiotically 
involved with these extra-academic formations, as once was the case in the UK.

One rationale for the new South African development of academic cultural studies is suggested by Williams: the project arises because 'people's questions are not being answered by the existing distribution of the educational curriculum' (p. 160). Cultural theorist Michael Green suggests a compelling goal for such cultural studies:

for some while Cultural Studies may be of best use, neither as an academic discipline with its own rigours, nor in the revolutions of intellectual/political paradigms (important as these are), but in its consolidation as a public presence. Not an area of new professional 'expertise' with 'answers', but a space openly available for thought and analysis ... Not a vanguard with its own language, but a continuing activity, responsive to short-term pressures and to the longer-term interests of participants. ${ }^{4}$

Cultural studies, indeed, has something particular to offer the rest of the academy here, precisely because of its fluid intellectual boundaries and its newness as a university discipline. More than any other academic field, cultural studies provides the potential for new forms of teaching, learning and knowledge that are local-based and people-led. I would go further and suggest that cultural studies also provides the potential for new forms of cultural production and policy. South African cultural studies could provide an institutional matrix in which the traditional distinctions between academic and aesthetic production, like those between theoretical reflection and policy development, are deliberately interrogated, challenged and transformed.

The importance of policy-making within a cultural studies agenda is something that Australian cultural critics and university departments have frequently addressed, with interesting results. Tony Bennett, for example, provocatively argues against current critical dispositions to view culture as a set of signifying practices and argues instead that

Culture is more cogently conceived, I want to suggest, when thought of as a historically specific set of institutionally embedded relations of government in which the forms of thought and conduct of extended populations are targeted for transformation - in part via the extension through the social body of the forms, techniques, and regimens of aesthetic and intellectual culture. 5 
From this he argues for a contemporary cultural studies that foregrounds policy and governmental engagement. Because it is both troubling and suggestive, I want to quote his argument in detail:

It might mean careful and focused work in the service of specific cultural action groups. It might mean intellectual work calculated to make more strategic interventions within the operating procedures and policy agendas of specific cultural institutions. It might mean hard statistical work calculated to make certain problems visible in a manner that will allow them to surface at the level of political debate or to impinge on policy-making processes in ways which facilitate the development of administrative programs capable of addressing them. It might mean providing private corporations with such information. One thing is for sure, however: it will mean talking to and working with what used to be called the Ideological State Apparatuses rather than writing them off from the outset and then, in a self-fulfilling prophecy, criticizing them again when they seem to affirm one's direst functionalist predictions. (p. 32)

I am aware that the above might be sheer anathema for a new South African cultural studies, situated as it is in a new country already saturated by the languages of policy formation. But I take Bennett's final sentence seriously as a call for proactive academic involvement with cultural policy that could effect a positive intervention in the emergence of a democratic culture(s) and government. ${ }^{6}$

\section{Questions of theory: intellectual paradigms for African cultural studies}

I have been outlining the potential of South African cultural studies to break from traditional formulations of academic endeavour. I want to now to look at existing academic practices and ask what current theoretical perspectives might assist the South African project. ${ }^{7}$ Raymond Williams's discussion of British academic cultural studies largely concerns the implications of the idealist version of the 'linguistic turn' that became dominant in the 1980s. Stuart Hall supplies a succinct definition of the linguistic turn:

[a conviction of] the crucial importance of language and of the linguistic metaphor to any study of culture; the expansion of the notion of text and textuality, both as a source of meaning, and as 
that which escapes and postpones meaning; the recognition of the heterogeneity, of the multiplicity, of meanings, of the struggle to close arbitrarily the infinite semiosis beyond meaning; the acknowledgement of textuality and cultural power, of representation itself, as a site of power and regulation; of the symbolic as a source of identity. ${ }^{8}$

I am interested in three aspects of the linguistic turn: the socio-political premises and implications of such theory; the adequacy of this theory as a tool for analysis of contemporary aesthetic practices; the way this theory articulates with professional pressures of self-legitimation.

The most negative explanation positions this cultural theory as the preservation of the status quo. In this vein, Williams condemns postmodern cultural theorists of 1980s Britain for providing 'long-term adjustments to short term situations' by rationalising the ostensible triumph of post-industrial capitalism. He sees this theory as failing in precisely its most crucial role: committed to theorisation of 'the new' developments in cultural production, such theories as were selected for this purpose are 'deficient above all in this key area, of the nature of cultural formations and thus of ongoing agency and practice' (emphasis added). ${ }^{9}$ The corollary of a theory that constructs 'the text' as the source of critical agency is the exclusion of social agency in the production of these texts. Furthermore, such theoretical textualism does not allow us to account for what is distinctive about new aesthetic expressions. There is no way, that is, of conceptualising the historical meaning of this new culture.

With regards to professional self-legitimation, I want to quote Williams at length, in what may be his most polemical and exasperated mood:

At just this moment [i.e., the formalisation of cultural studies in/by UK academe], a body of theory came through which rationalized the situation of this formation on its way to becoming bureaucratized and the home of specialist intellectuals ... the theories which came - the revival of formalism, the simpler kinds (including Marxist kinds) of structuralism - tended to regard the practical encounters of people in society as having relatively little effect on its general progress, since the main inherent forces of that society were deep in its structures, and - in the simplest forms - the people who operated them were mere 'agents'. This was precisely the encouragement for 
people not to look at their own formation, not to look at this new and at once encouraging and problematic situation they were in; at the fact that this kind of education was getting through to new kinds of people, and yet that it was still inside minority institutions, or that the institutions exercised the confining bureaucratic pressures of syllabus and examination, which continually pulled these raw questions back to something manageablewithin their terms. At just that moment ... there was ... a quite uncritical acceptance of a set of theories which in a sense rationalized that situation, which said that this was the way the cultural order worked, this was the way in which the ideology distributed its roles and functions. The whole project was then radically diverted by these new forms of idealist theory. 10

(For Williams, structuralism's problematic formalism and pessimism recur in academic post-structuralism and postmodernism.) What I want to ask is: how might Williams's account assist our development and understanding of new cultural studies in South Africa?

This leads me to question the consequences of South African intellectual dependence on idealist metropolitan values and formulations. At the very moment when the new South Africa is released from isolation, is ready to reconfigure its cultural, economic and intellectual relations to Africa and the developing world - why now ratify a neo-colonial axis of theoretical authority? Why uncritically embrace a methodology that renounces the possibility of analysing social totality? Now that new transcontinental history and geography can be developed - why embrace a theoretical orientation that rejects the contributions of history, a discipline that is surely one of South Africa's greatest intellectual assets? The axes of overseas theoretical dialogue and stimulation might profitably multiply to include other 'developing' countries of the Americas, Africa and Asia. And they might include Australia and Canada, whose historical similarities as settler colonies may yield theoretical insight.

I want briefly to transform the question 'what kinds of (post-structuralist) theoretical paradigms could South African cultural studies deploy?' to something like 'what contributions could South Africa make to a theoretical (re)formulation of cultural studies as practised in the UK and the USA?' The linguistic turn itself supplies one answer. Raymond Williams does not categorically reduce this turn to its idealist expression, but instead dialectically sees within it the opportunity for materialist articulation. So he argues that 
the 'language paradigm' remains a key point of entry, precisely because it was the modernist escape route from what is otherwise the Formalist trap: that an autonomous text, in the very emphasis on its specificity, is ... a work in a language that is undeniably social ... It is then precisely in this real work on language, including the language of works marked as temporarily independent and autonomous, that modern cultural theory can be centred: a systematic and dynamic social language, as distinct from the 'language paradigm'. ${ }^{11}$

I want to suggest that South African cultural critics and theorists are exceptionally well placed to develop this kind of 'real work', a cultural studies grounded in the sociality of language. Knowledgeable as South Africans necessarily are of the complexity and potency of language formations, they - you - could use that knowledge to produce textual, theoretical and sociological analyses from which European and US academies might learn.

\section{Cultural studies and social analysis}

I turn, finally, to issues of social and political analysis: what role could a South African cultural studies play in such analyses? What relations obtain between cultural, political and economic power in the new South Africa? What insights from cultural studies and theory could assist in the understanding - and transformation - of these relations? In particular, I want to look at ways in which the Gramsci-inflected political analyses may help or hinder South African discussions. Can paradigms appropriated from what may loosely be termed the 'subjective turn' in political theory (parallel to the 'linguistic turn' in cultural theory) assist in developing a new public sphere, a new civil society, a new understanding of the state in South Africa?

All I can do here is to toss up a few polemical observations. It would not be useful, appropriate or possible to enter into a full critical discussion of the pros and cons of the British postmodern socialist theory exemplified by recent work by Stuart Hall, by the sadly defunct Communist Party journal Marxism Today and its influential analyses of post-Fordist 'New Times'. 12 Instead I will focus my observations on a recent article by Grant Farred that draws upon the above theoretical currents to advance an argument about the role of cultural and social difference in a new South African polity. 
Farred's article takes up a number of notions central to British socialist cultural theory: the rejection of economistic Marxism; the notion that culture is an important factor in shaping social relations; the suspicion of the state; the belief in the preservation of cultural difference and identity against the unifying tendencies of government; the advocacy of coalitionist political mobilisations that are local, contingent and predicated on cultural affinity. Where Farred differs is in the context and the political impetus of his argument. He writes (this is before the 1994 election) as a socialist who is concerned that the ANC - as opposition and future government - is silencing the voices and the priorities of working-class and socialist movements. His concern is to find a way for progressive and marginalised constituencies to create a politics that challenges the ANC's monopoly. 13

There is a lot to agree with in Farred 's argument. But I find problematic both the fatalism and the ambiguity of his presentation; his article suggests both a pragmatic and an idealist perspective. Farred focuses a lot on Inkatha-gate (the correct funding of the Inkatha party by De Klerk's government), the Third Force (correct operations organised to destabilise liberation movements) and, more generally, the ways in which apartheid fostered and then exploited cultural differences among peoples. $\mathrm{He}$ focuses equally on the cultural differences generated through a variety of anti-apartheid struggles, in the labour movement and the women's movement in particular. This leads him to contend that

The distinctiveness of Inkatha, the women's struggle, the trade union and community activists, suggests that black South Africa cannot be naturalised into an undivided cultural entity ... it will be extremely difficult for the movement to efface not only the distinct cultural identities that apartheid has foisted upon black South Africans, but also those identities that have been achieved through struggle with the apartheid state and within the black community.

This then leads to his argument that 'cultural divisions can actually be used by women's groups, leftists within the ANC, other left black political organisations, community activists, and trade unionists to give voice to political and ideological differences' (p. 223). It would seem crucial to differentiate 'difference': to establish a theoretical political discourse that does not lump together those differences created by apartheid with those created through struggle against apartheid. But this differentiation is what Farred's analysis cannot pursue. The notions of 'culture' and of 
'difference' with which Farred is working do not readily allow for such a differentiation.

I am not altogether sure how his article defines culture. At times it denotes ethnicity, at other times it denotes political and/or ideological identities, and at other times culture is a general word for the consciousness that accompanies a certain relation to economic production. This multiplicity of meanings is the intellectual heritage of a postmodern Gramscianism. The reasons Farred cannot creatively differentiate between difference as imposed and as produced through struggle are, again, to do with the fact that the original context in which difference was conceptualised was that in which a free-market hegemony rather than coercion was the method of government. It is also arguable that the valorisation of difference within its original Western European context was, as Raymond Williams suggests, politically problematic, reflecting a critical inability to do more than fatalistically accept, rationalise and adapt to the logics of the market.

Such fatalism is clearly indicated when Farred suggests that

The articulation of their differences will enable these [the above] groups to distinguish and distance themselves from the blossoming partnership between the A.N.C. and ... the N.P. ... Such a critical platform can also be used to create a space for leftist politics within the ranks of black South Africa, a space which is desperately needed so that debates about difference can be initiated before therhetoric of 'unity' preempts any such critiques. At this point, the insistence upon difference - cultural, political, and ideological - may be all that stands between the masses of exploited black South Africans and the triumvirate ... of a newly embourgeoised and entrepreneurial black middle class, the white upper and middle classes, and multinational capitalism. (p. 224; emphasis added)

The pessimism lies in the conceptualisation of the emergent government. The ANC, by virtue of its very ascendancy to state power, is unable to avoid ideological convergence with the outgoing pro-apartheid Nationalist Party. As with his construction of cultural difference, however, Farred's construction of the ANC is ambiguous. He argues that through its own historical agency the party has gained political hegemony, and now elects to operate centripetally in order to exclude difference. Farred also seems to suggest that the ANC has been placed in its hegemonic position by the operations of (home and outside) governments and media, 
and that its exclusions of difference are not so much voluntary as the result of outside determination. In other words, he blurs the distinction between an ANC identity created through resistance to the state, and that invented by the state.

Within this somewhat deterministic trajectory, in which the state is seen as necessarily antagonistic to the differences it has worked to create, all that is left to those oppositional constituencies of difference is to bond together provisionally in what Farred calls a 'politics of affinity'. They are to articulate difference within what appears to be a discursive, ideological and cultural rather than formally political space. Farred is committed to a socialist redistribution of wealth, but his arguments do indicate how the politics of affinity, and the preservation of differences, are to achieve such redistribution. The languages of difference as evolved and practised in the British left were connected to flows of consumption than production and distribution, and so cannot provide an indication of how this redistribution might work in the new South Africa.

If I am unclear as to how cultural forces are to translate into political and economic ones here, I am also unsure whether this is necessary or altogether desirable. To insist that cultural difference is a material fact of post-apartheid South Africa is one thing, but to suggest that this is the only political resource left to underprivileged groups is a different matter. The South African left and labour movements (in comparison with Western Europe) still have, it seems to me, the potential for active representation in government power and economic policy. If such potential is threatened by the dominance of the ANC, why must the only response be the renunciation of formal ties with the ANC and the development of a counter-hegemonic bloc, derived from cultural differences, and situated somewhere in civil society? This may be a very important project to develop, but it need not and cannot be the only one. Ultimately, Farred's social analysis reveals both the promise and the insufficiency of contemporary Gramscian thought for the new South African situation. This is what I hope the new project of cultural studies in South Africa can work beyond.

\section{Notes}

1 Raymond Williams, 'The Future of Cultural Studies', The Politics of Modernism: Against the New Conformists, edited and introduced by Tony Pinkney (London: Verso, 1989), p. 155. 
2 Linden Peach, 'Yorkshire and the Origins of Cultural Politics', Red Letters: A Review of Cultural Politics, 27 (1990), p. 6.

3 The title of the 1993 conference at which the talk on which this chapter was based was given was 'Appropriations: New Directions in African Cultural Studies?'. For useful discussions of the issues involved in applying British cultural studies outside of the UK see Jon Stratton and Ien Ang, 'On the Impossibility of a Global Cultural Studies: "British" Cultural Studies in an "International" Frame', in David Morley and Kuan-Hsing Chen (eds.), Stuart Hall: Critical Dialogues in Cultural Studies (London: Routledge, 1996), pp. 361-91; Kuan-Hsing Chen, 'Cultural Studies and the Politics of Internationalization: An Interview with Stuart Hall', in ibid., pp. 392-408. See also South African reflections by P. Eric Louw, 'Rethinking Cultural Studies to Meet the Challenge of the "Information Age" in South Africa', Social Dynamics [Cape Town, South Africa], 21, 1 (1995), pp. 71-8; Keyan G. Tomaselli, 'Reading Stuart Hall in Southern Africa', in Paul Gilroy, Lawrence Grossberg and Angela McRobbie (eds.), Without Guarantees: In Honour of Stuart Hall (London: Verso, 2000), pp. 375-87 and Keyan G. Tomaselli, 'Cultural Studies and Renaissance in Africa: Recovering Praxis', Scrutiny2: Issues in English Studies in Southern Africa [Pretoria, South Africa], 4, 2 (1999), pp. 43-8.

4 Michael Green, “'Cultural Studies!”, Said the Magistrate', News from Nowhere: Journal of Cultural Materialism, 8 (1990), p. 36.

5 Tony Bennett, 'Putting Policy into Cultural Studies', in Lawrence Grossberg, Cary Nelson and Paula Treichler (eds.), Cultural Studies (London: Routledge, 1992), p. 26.

6 For an interesting discussion of writing centres (based on US models) within South African universities, and their contribution to the democratisation of higher education, see Pam Nichols, 'A Snowball in Africa with a Chance of Flourishing: Writing Centres as Shifters of Power in a South African University', Current Writing: Text and Reception in Southern Africa [Durban, South Africa], 10, 2 (1998), pp. 84-95. See also Kelwyn Sole, 'Democratising Culture and Literature in a "New South Africa": Organisation and Theory', Current Writing: Text and Reception in Southern Africa, 6, 2 (1994), pp. 1-37; Tony Parr, 'Saving Literature', Scrutiny2: Issues in English Studies in Southern Africa, 1, 1-2 (1996), pp. 70-7, and Margaret Daymond, 'Contexts for "Literature": On "Literary" and "Cultural" Studies in an English Department Syllabus', Scrutiny2: Issues in English Studies in Southern Africa, 1, 1-2 (1996), pp. 78-88.

7 See Kelwyn Sole, 'South Africa Passes the Posts', Alternation: Journal of the Centre for the Study of Southern African Literature and Languages [Durban, South Africa], 4, 1 (1997), pp. 116-51, for a critical discussion of contemporary theoretical strands in South African humanities.

8 Stuart Hall, 'Cultural Studies and its Theoretical Legacies', in Lawrence Grossberg, Cary Nelson and Paula Treichler (eds.), Cultural Studies, p. 283.

9 Raymond Williams, 'The Uses of Cultural Theory', The Politics of Modernism: Against the New Conformists, p. 171. 
10 Raymond Williams, 'The Future of Cultural Studies', p. 157.

11 Raymond Williams, 'The Uses of Cultural Theory', p. 174.

12 For a sympathetic retrospective discussion of New Times see Angela McRobbie, 'Looking Back at New Times and its Critics', in David Morley and Kuan-Hsing Chen (eds.), Stuart Hall: Critical Dialogues in Cultural Studies, pp. 238-61. For a critical discussion see Neil Lazarus, 'Doubting the New World Order: Marxism Postmodernist Social Theory', Differences: A Journal of Feminist Cultural Studies, 3, 3 (1991), pp. 94-138.

13 Grant Farred, 'Unity and Difference in Black South Africa', Social Text, 31-2 (1992), pp. 217-34. 